\title{
HNPCC versus sporadic microsatellite-unstable colon cancers follow different routes toward loss of HLA class I expression Jan Willem F Dierssen ${ }^{\dagger 1}$, Noel FCC de Miranda ${ }^{\dagger 1}$, Soldano Ferrone ${ }^{2}$, Marjo van Puijenbroek ${ }^{1}$, Cees J Cornelisse ${ }^{1}$, Gert Jan Fleuren ${ }^{1}$, Tom van Wezel ${ }^{1}$ and Hans Morreau*1
}

\author{
Address: ${ }^{1}$ Department of Pathology, Leiden University Medical Center, Leiden, The Netherlands and ${ }^{2}$ Department of Immunology, Roswell Park \\ Cancer Institute, Buffalo, NY, USA \\ Email: Jan Willem F Dierssen - JWFDierssen@gmail.com; Noel FCC de Miranda - N.F.Miranda@lumc.nl; \\ Soldano Ferrone - Soldano.Ferrone@ roswellpark.org; Marjo van Puijenbroek - M.van_Puijenbroek@lumc.nl; \\ Cees J Cornelisse - C.J.Cornelisse@lumc.nl; Gert Jan Fleuren - G.J.Fleuren@lumc.nl; Tom van Wezel - T.van_Wezel@lumc.nl; \\ Hans Morreau* - J.Morreau@lumc.nl \\ * Corresponding author †Equal contributors
}

Published: 22 February 2007

BMC Cancer 2007, 7:33 doi:10.1 |86/|47|-2407-7-33
Received: 20 October 2006

Accepted: 22 February 2007

This article is available from: http://www.biomedcentral.com//47/-2407/7/33

(C) 2007 Dierssen et al; licensee BioMed Central Ltd.

This is an Open Access article distributed under the terms of the Creative Commons Attribution License (http://creativecommons.org/licenses/by/2.0), which permits unrestricted use, distribution, and reproduction in any medium, provided the original work is properly cited.

\begin{abstract}
Background: Abnormalities in Human Leukocyte Antigen (HLA) class I expression are common in colorectal cancer. Since HLA expression is required to activate tumor antigen-specific cytotoxic Tlymphocytes (CTL), HLA class I abnormalities represent a mechanism by which tumors circumvent immune surveillance. Tumors with high microsatellite instability (MSI-H) are believed to face strong selective pressure to evade CTL activity since they produce large amounts of immunogenic peptides. Previous studies identified the prevalence of HLA class I alterations in MSI-H tumors. However, those reports did not compare the frequency of alterations between hereditary and sporadic MSI-H tumors neither the mechanisms that led to HLA class I alterations in each subgroup.

Methods: To characterize the HLA class I expression among sporadic MSI-H and microsatellite-stable (MSS) tumors, and HNPCC tumors we compared immunohistochemically the expression of HLA class I, $\beta 2$-microglobulin ( $\beta 2 \mathrm{~m})$, and Antigen Processing Machinery (APM) components in $8 \mathrm{I}$ right-sided sporadic and 75 HNPCC tumors. Moreover, we investigated the genetic basis for these changes.

Results: HLA class I loss was seen more frequently in MSI-H tumors than in MSS tumors $(p<0.000$ I). Distinct mechanisms were responsible for HLA class I loss in HNPCC and sporadic MSI-H tumors. Loss of HLA class I expression was associated with $\beta 2 \mathrm{~m}$ loss in HNPCC tumors, but was correlated with APM component defects in sporadic MSI-H tumors $(\mathrm{p}<0.000 \mathrm{I})$. In about half of the cases, loss of expression of HLA class I was concordant with the detection of one or more mutations in the $\beta 2 \mathrm{~m}$ and APM components genes.

Conclusion: HLA class I aberrations are found at varying frequencies in different colorectal tumor types and are caused by distinct genetic mechanisms. Chiefly, sporadic and hereditary MSI-H tumors follow different routes toward HLA class I loss of expression supporting the idea that these tumors follow different evolutionary pathways in tumorigenesis. The resulting variation in immune escape mechanisms may have repercussions in tumor progression and behavior.
\end{abstract}




\section{Background}

During cancer development, tumor cells may elicit cytotoxic T-lymphocyte (CTL)-mediated immune responsespartly a consequence of accumulated gene mutations that are translated into altered peptides [1]. Tumor cell expression of HLA class I-antigen complexes is essential for CTL recognition of aberrant peptides and subsequent activation [2]. Consequently, alteration of HLA class I cell surface expression provides an effective mechanism by which tumors can escape immune detection [3,4]. Multiple mechanisms have been shown to underlie defects in HLA class I expression by tumor cells. They include mutations in the individual HLA class I genes HLA-A, $-B$ and $-C$, located on chromosome 6p21.3) [5]; mutations in $\beta 2$ microglobulin $(\beta 2 m)$ [6-9], molecule required for cell surface expression of HLA class I antigens; and defects in components of the HLA class I-associated antigenprocessing machinery (APM) [9-11]. The APM consists of proteasome components delta, MB1 and $\mathrm{Z}$; the immunoproteasome components LMP2, LMP7 and LMP10; peptide transporters TAP1 and TAP2; and chaperones Calnexin, Calreticulin, ERp57, and Tapasin. The immunoproteasome generates peptides mostly, although not exclusively from endogenous proteins, TAP1 and TAP2 facilitate peptide translocation from the cytosol into the lumen of the endoplasmic reticulum, where the peptides are loaded onto the HLA class I molecules with the aid from the several chaperones [12].

Chromosomal instability (CIN) and microsatellite instability (MIN) are the two major forms of genetic instability in colorectal cancer. Combined with distinct somatic mutation patterns and epigenetic modifications, CIN and MIN lead to the development of sporadic colorectal cancer [13]. MIN sporadic tumors, which constitute approximately $15 \%$ of all colorectal cancer cases and up to $40 \%$ of the tumors localized on the right side (preceding the splenic flexure) of the colon [14], have a phenotype resulting from the epigenetic inactivation of the mismatch repair gene $h M L H 1$. Its inactivation destroys a cell's ability to repair base-base mismatches and small insertions or deletions in repetitive stretches, leading to an accumulation of frameshift mutations that get translated into abnormal peptide sequences. When these mutations are accumulated to large extent in the cell genome the tumors are said to possess high-microsatellite instability (MSI-H) [15]. Hence, it is expected that genes containing microsatellite sequences within their coding regions are more susceptible to somatic mutations, as seen in the TGF $\beta$-RII gene. TGF $\beta$-RII's third exon contains a microsatellite repeat of 10 adenines that is frequently targeted by frameshift mutations in MSI-H tumors [16]. MSI-H is also the hallmark of hereditary non-polyposis colorectal cancer (HNPCC), in which germline mutations of $h M L H 1$, $h M S H 2, h M S H 6$ and PMS2 can be found. HNPCC consti- tutes approximately 2-4\% of all CRC cases [17]. Tumors with MSI-H are thought to be more able to stimulate a CTL-mediated immune response due to their frequent generation of the aberrant frameshift peptides [18]. Therefore, these tumors are subjected to a greater selective pressure which favors the outgrowth of tumor cells with the ability to escape from recognition and destruction by host immune system.

Various studies have identified HLA alterations in colorectal cancer [19-21], including the prevalence of HLA class I alterations in MSI-H tumors [8,22]. However, the latter studies did not compare the frequency of alterations between hereditary and sporadic MSI-H tumors neither the mechanisms that led to HLA class I alterations in each subgroup. It was suggested that MSI-H sporadic and hereditary tumors follow parallel evolutionary pathways during tumorigenesis in terms of both genotype and phenotype [23]. As far as HLA class I defects are concerned it was never investigated whether these different tumors present distinct escape mechanisms from the immune system. In the present study, we compared the frequency of defects in HLA class I expression in right-sided sporadic (MSI-H and microsatellite-stable (MSS) sub-groups) colon tumors and in HNPCC tumors and studied the mechanisms underlying any abnormalities in these subgroups.

\section{Methods}

\section{Patient material and tissue microarrays}

Two tissue microarrays were constructed from formalinfixed, paraffin-embedded tissues as described previously [24]. One array, previously described [25], included colorectal tumor specimens from 129 suspected HNPCC patients with MSI-H colon tumors of which 75 cases were analyzed in the present study after confirmation of their HNPCC status: $73.3 \%(n=55)$ of the latter possessed a germline pathogenic mutation in hMLH1 ( $\mathrm{n}=24)$, hMSH2 $(\mathrm{n}=18), h M S H 6(\mathrm{n}=12)$ or PMS2 $(\mathrm{n}=1)$, the remaining were $\mathrm{MSI}-\mathrm{H}$, without methylation of the $h M L H 1$ promoter and/or with immunohistochemical loss of the MSH2/MSH6 heterodimer and/or possessed a very young age at diagnosis of colon cancer ( $<50$ yrs old). All cases possessed a positive family history for MSI-H tumors. The second tissue array included 3 tumor tissue cores from 81 sporadic right-sided colon cancer cases resected between 1990 and 2005 at the Leiden University Medical Center (Leiden, The Netherlands) and at the Rijnland Hospital (Leiderdorp, The Netherlands). The 81 patients in the latter array consisted of 47 females and 34 males with a mean age of 71.15 years $(\mathrm{SD}=9.958)$. Approximately $60 \%(n=48)$ of these cases were classified as MSS while the remaining $(n=33)$ possessed a MSI-H phenotype. The microsatellite instability status of the tumors was determined according to recommendations of 
the National Cancer Institute/ICG-HNPCC [15]. Moreover all MSI-H sporadic cases have lost the expression of the MLH1/PMS2 heterodimer as assessed by immunohistochemistry. The sporadic status of the MSI-H right-sided tumors (RST) was confirmed by methylation analysis of the $h M L H 1$ promoter using a methylation-specific MLPA assay as previously described [26]. All MSI-H sporadic cases presented with hypermethylation at the $h M L H 1$ promoter.

The present study falls under approval by the Medical Ethical Committee of the LUMC (protocol P01-019). Cases were analyzed following the medical ethnical guidelines described in the Code Proper Secondary Use of Human Tissue established by the Dutch Federation of Medical Sciences [27].

\section{Immunohistochemistry}

Standard three-step, indirect immunohistochemistry was performed on $4-\mu \mathrm{m}$ tissue sections transferred to glass slides using a tape-transfer system (Instrumedics, Hackensack, NJ), including citrate antigen retrieval, blockage of endogenous peroxidase and endogenous avidin-binding activity, and di-aminobenzidine development.

The following primary antibodies were used: the mAb HCA2 which recognizes $\beta 2 \mathrm{~m}$-free HLA-A (except -A24), B7301 and -G heavy chains $[28,29]$; the mAb HC10, which recognizes a determinant expressed on all $\beta 2 \mathrm{~m}$-free HLA-B and C heavy chains and on $\beta 2 \mathrm{~m}$-free HLA-A10, A28, -A29, -A30, -A31, -A32 and -A33 heavy chains (supernatant kindly provided by Dr. J. Neefjes, NKI, Amsterdam, The Netherlands and Dr. H. L. Ploegh, MIT, Boston, MA) $[28,30]$; TAP1 specific mAb NOB1; LMP2specific mAb SY-1; LMP7-specific mAb HB2; LPM10-specific mAb TO-7; Calnexin-specific mAb TO-5; Calreticulin-specific mAb TO-11; Tapasin-specific mAb TO-3; ERp57-specific mAb TO-2 [31-33]; TAP2-specific mAb (BD Biosciences Pharmingen, San Diego, CA); rabbit anti$\beta 2 \mathrm{~m}$ polyclonal Ab (A 072; DAKO Cytomation, Glostrup, Denmark); anti-MLH1 (clone G168-728; BD Biosciences) and anti-PMS2 (clone A16-4; BD Biosciences). Secondary reagents used were biotinylated rabbit antimouse IgG antibodies (DAKO Cytomation), goat antirabbit IgG antibodies (DAKO Cytomation), and biotinylated-peroxidase streptavidin complex (SABC; DAKO Cytomation).

Loss of expression was defined by complete lack of staining in membrane and cytoplasm (HCA2, HC10, and anti$\beta 2 \mathrm{~m}$ ), in the nucleus (anti-MLH1 and anti-PMS2), in the peri-nucleus/endoplasmic reticulum (NOB1, anti-TAP2, TO-2, TO-3, TO-5, TO-7, and TO-11), or in the cytoplasm (SY-1, HB2, and TO-7), but with concurrent staining in normal epithelium, stroma or infiltrating leukocytes. HLA class I expression was considered to be lost when one of the HLA class I antigen-specific antibodies gave a negative result alongside a positive internal control (lymphocytic infiltrate).

\section{Flow cytometric sorting}

The flow cytometric sorting procedure, including tissue preparation, staining and flow cytometry analysis was performed as described previously [34]. Briefly, $2 \mathrm{~mm}$ diameter punches from selected areas of formalin-fixed paraffin embedded colorectal carcinomas were digested enzymatically in a mixture of $0.1 \%$ collagenase I-A (Sigma-Aldrich, St Louis, MO, USA) and $0.1 \%$ dispase (Gibco BRL, Paisley, UK). After determination of cell concentration, one million cells were incubated with $100 \mu \mathrm{l}$ of $\mathrm{mAb}$ mixture directed against keratin and vimentin containing clones MNF116 (anti-keratin; IgG1; DAKOCytomation, Golstrup, Denmark), AE1/AE3 (anti-keratin; IgG1; Chemicon International Inc, Temecula, CA, USA), and V9-2b (anti-vimentin; IgG2b; Department of Pathology, LUMC [35]). Next day, cells were incubated with 100 $\mu l$ of premixed FITC and RPE-labelled goat F(ab')2 antimouse subclass-specific secondary reagents (Southern Biotechnology Associates, Birmingham, AL, USA). After washing, cells were incubated with $10 \mu \mathrm{M}$ propidium iodide (PI) and $0.1 \%$ DNase-free RNase (Sigma). The next day cells were analyzed by flow cytometry. A standard FACSCalibur (BD Biosciences) was used for the simultaneous measurement of FITC, RPE, and PI. Tumor and normal cell populations were flow-sorted using a FACSVantage flow-sorter (BD Biosciences) using the FACSCalibur filter settings. Sorting was only performed on samples included in the RST array due to shortage of material from the HNPCC cases. DNA from flow-sorted tumor material was isolated as described by Jordanova $e t$ al. [36]. DNA from non-sorted material was isolated using Chelex extraction as described previously [37].

\section{LOH and fragment analysis}

Markers for loss of heterozygosity ( $\mathrm{LOH}$ ) analysis were chosen from the dbMHC database [38] to map the chromosome 6p21.3 region between HLA-A and TAP2. They were MOGc, D6S510, C125, C141, D6S2444, TAP1 and M2426. A "linker" sequence of 5'-GTTTCTT was added to the $5^{\prime}$ terminus of all reverse primers [39]. LOH was defined as allelic imbalance $>2$ in the HNPCC cases (nonsorted) and allelic imbalance $>5$ in the sorted RST [40].

To detect frame-shift mutations in the HLA-A, HLA-B, B2m, LMP2, LMP7, LMP10, TAP1, TAP2, Calnexin, Calreticulin, ERp57 and Tapasin genes, 28 pairs of primers (Table 1) were constructed surrounding non-polymorphic microsatellite regions within the coding regions. 
Table I: Primers used in fragment analysis

\begin{tabular}{|c|c|c|c|}
\hline Gene & Forward primer & Reverse primer & Microsatellite Repeat \\
\hline HLA A $4^{\text {th }}$ ex & СCTGAATTTTCTGACTCTTCCCGT & GTTTCTTTCCCGCTGCCAGGTCAGTGT & $7(C)$ \\
\hline$H L A A^{\text {th }}$ ex & CCATCGTGGGCATCATTG & GTTTCTTTCAGTGAGACAAGAAATCTC & $3(\mathrm{GGA})$ \\
\hline HLA B $2^{\text {nd }} \mathrm{ex}$ & GCTTCATCTCAGTGGGCTAC & GTTTCTTCTCGCTCTGGTTGTA & $3(\mathrm{GA})+3(\mathrm{CA})$ \\
\hline$\beta 2 m$ l st ex $^{\text {st }}$ & GGCTGGGCACGCGTTTAAT & GTTTCTTAGGGAGAGAAGGACCAGAG & $4(\mathrm{CT})$ \\
\hline$\beta 2 m 2^{\text {nd }}$ ex (I) & TACCCTGGCAATATTAATGTG & GTTTCTTGATAGAAAGACCAGTCCTTGC & $4(G A)+5(A)$ \\
\hline$\beta 2 m 2^{\text {nd }}$ ex (2) & CTTACTGAAGAATGGAGAGAG & GTTTCTTGACTACTCATACACAACTTTCA & $5(A)$ \\
\hline TAPI | $\left.\right|^{\text {st }}$ ex & TAAATGGCTGAGCTTCTCGC & GTTTCTTAGAGCTAGCCATTGGCA & $5(C)$ \\
\hline TAPI $3^{\text {rd }} \mathrm{ex}$ & ACAGCCACTTGCAGGGAG & GTTTCTTTATGAACAGTACATGGCGTAT & $5(\mathrm{~T})$ \\
\hline TAPI $8^{\text {th }}$ ex & CTGCCCTGCTGCAGAATCTG & GTTTCTTCAAGCCACCTGCTTCCAT & $5(\mathrm{G})$ \\
\hline TAPI $10^{\text {th }}$ ex & CTCTGCAGAGGTAGACGAGG & GTTTCTTATTAAGAAGATGACTGCCTCAC & $5(\mathrm{G})$ \\
\hline TAPI I I th ex & AGCACCTCAGCCTGGTGGA & GTTTCTTGCAGGTCTGAGAAGGCTTTC & $6(G)+5(A)$ \\
\hline TAP2 $2^{\text {nd }}$ ex & TTCCTCAAGGGCTGCCAGGAC & GTTTCTTGCTCCAAGGGGCTGAAG & $6(C)$ \\
\hline TAP2 9th ex & CCTACGTCCTGGTGAGGTGA & GTTTCTTCTGGCTGTGCAGGTAGC & $5(\mathrm{G})$ \\
\hline Tapasin $2^{\text {nd }}$ ex & TTGGTTCGTGGAGGATGC & GTTTCTTCCTAGAGACTCACCGTGTAC & $5(\mathrm{G})$ \\
\hline Tapasin $3^{\text {rd }}$ ex & СТTССТTСТСТАСАСТCAGACC & GTTTCTTAGGACTGGGCTGGATATGC & $5(C)$ \\
\hline Tapasin $4^{\text {th }}$ ex & ССTGTCTTCCTCAGTGGTAC & GTTTCTTGAGCAGATGTCCCTTACCC & $6(C)$ \\
\hline Tapasin $5^{\text {th }}$ ex & TGCTCATTTCGTCCTCTTTCC & GTTTCTTGTTCCCACTCCACCTCCAG & $5(\mathrm{G})$ \\
\hline Calnexin $7^{\text {th }}$ ex & GAAGGATCAGTTCCATGACAAG & GTTTCTTCTGCATCTGGCCTCTTAGC & $5(A)$ \\
\hline Calnexin $8^{\text {th }}$ ex & TCTGCTCAATGACATGACTCC & GTTTCTTTGAAGACAGTTCCCCAAGAC & $5(A)$ \\
\hline Calnexin IIth ex & AACCTTTCAGAATGACTCCTTTTAG & GTTTCTTCAAGCAGCAAACACGAACC & $8(\mathrm{~T})$ \\
\hline Calreticulin $3^{\text {rd }}$ ex & CTACCGTCCCGTCTCAGG & GTTTCTTTCTGTCTGGTCCAAACTATTAGG & $5(\mathrm{G})$ \\
\hline Calreticulin $6^{\text {th }}$ ex & GACAAGCCCGAGCATATCC & GTTTCTTCACCTTGTACTCAGGGTTCTG & $5(C)$ \\
\hline ERp57 $5^{\text {th }}$ ex & CACTTATTGCTTCTTCCTTGTG & GTTTCTTAATACTTGGTCAGGAGATTCAAC & $6(\mathrm{~T})$ \\
\hline$E R p 576^{\text {th }}$ ex & CTTCTGCTATCTGCCTACTGAG & GTTTCTTTCAAGCAAATAAATCCCAGACAAG & $6(A)$ \\
\hline ERp57 I $3^{\text {th }}$ ex & ACTTTTAAGCTGATCTTTCTGTTTT & GTTTCTTTTAGAGATCCTCCTGTGCCTT & $6(C)$ \\
\hline$L M P 22^{\text {nd }}$ ex & GAGGGCATCAAGGCTGTTC & GTTTCTTGCAGACACTCGGGAATCAG & $5(\mathrm{G})$ \\
\hline LMP2 $6^{\text {th }}$ ex & СССТСТСТССААСТTGAAACC & GTTTCTTTGTAATAGTGACCAGGTAGATGAC & $5(\mathrm{G})$ \\
\hline LMP7 | st ex $^{\text {st }}$ & GGCTTTCGCTTTCACTTCC & GTTTCTTGAGATCGCATAGAGAAACTGTAG & $6(C)$ \\
\hline
\end{tabular}

\section{Statistics}

Significance values were calculated using the software package SPSS 10.0.7 (SPSS Inc., Chicago, IL, USA).

\section{Results}

\section{HLA class I, $\beta 2 m$ and APM component expression}

In order to compare the expression of HLA class I in sporadic $\mathrm{MSI}-\mathrm{H}$ and MSS right sided tumors (RST) and HNPCC MSI-H cases, we used an antibody panel recognizing monomorphic determinants expressed on HLA class I heavy chains, $\beta 2 \mathrm{~m}$ and APM components (Figure $1)$.

In total, we identified loss of HLA class I expression in about $34.6 \%$ of the RST and $42.7 \%$ of the HNPCC cases. The frequency of alterations differed significantly between the sporadic MSS and MSI-H RST. The lack of HLA class I expression was more frequent in MSI-H sporadic cases than in MSS cases ( $\mathrm{p}<0.0001)$, as it was $16.7 \%$ in the latter group, but $60.6 \%$ in the former (Table 2 ).
Subsequently, we have investigated the frequency of a concomitant loss of HLA class I expression with that of either the $\beta 2 \mathrm{~m}$ molecule or of any APM component. In the sporadic subset, loss of HLA class I expression was more often associated with that of one of the APM components, occurring in about 37\% of HLA-negative tumors regardless of their mismatch repair status (Table 2 ). $\beta 2 \mathrm{~m}$ loss was only found in one HLA class I negative MSI-H sporadic tumor (case 65) that interestingly also presented loss of the APM molecules TAP2, Calreticulin and Tapasin (Figure 2). In contrast, loss of HLA class I expression in HNPCC cases was more frequently associated with that of $\beta 2 \mathrm{~m}$ (Table 2 ), as it was found in $46.9 \%$ of the HLA class I-negative tumors. In contrast loss of any APM component was observed in only $6 \%$ of these cases (h38, h49) which also showed loss of $\beta 2 \mathrm{~m}$ expression.

In sporadic RST, the simultaneous loss of more than one APM molecule per case was frequent (Figure 2). Only 3 out of 10 cases lost a single APM component. The TAP2 molecule was most frequently lost ( 6 cases), followed by TAP1, Tapasin and LMP2 (5 cases), Calreticulin (4 cases), 

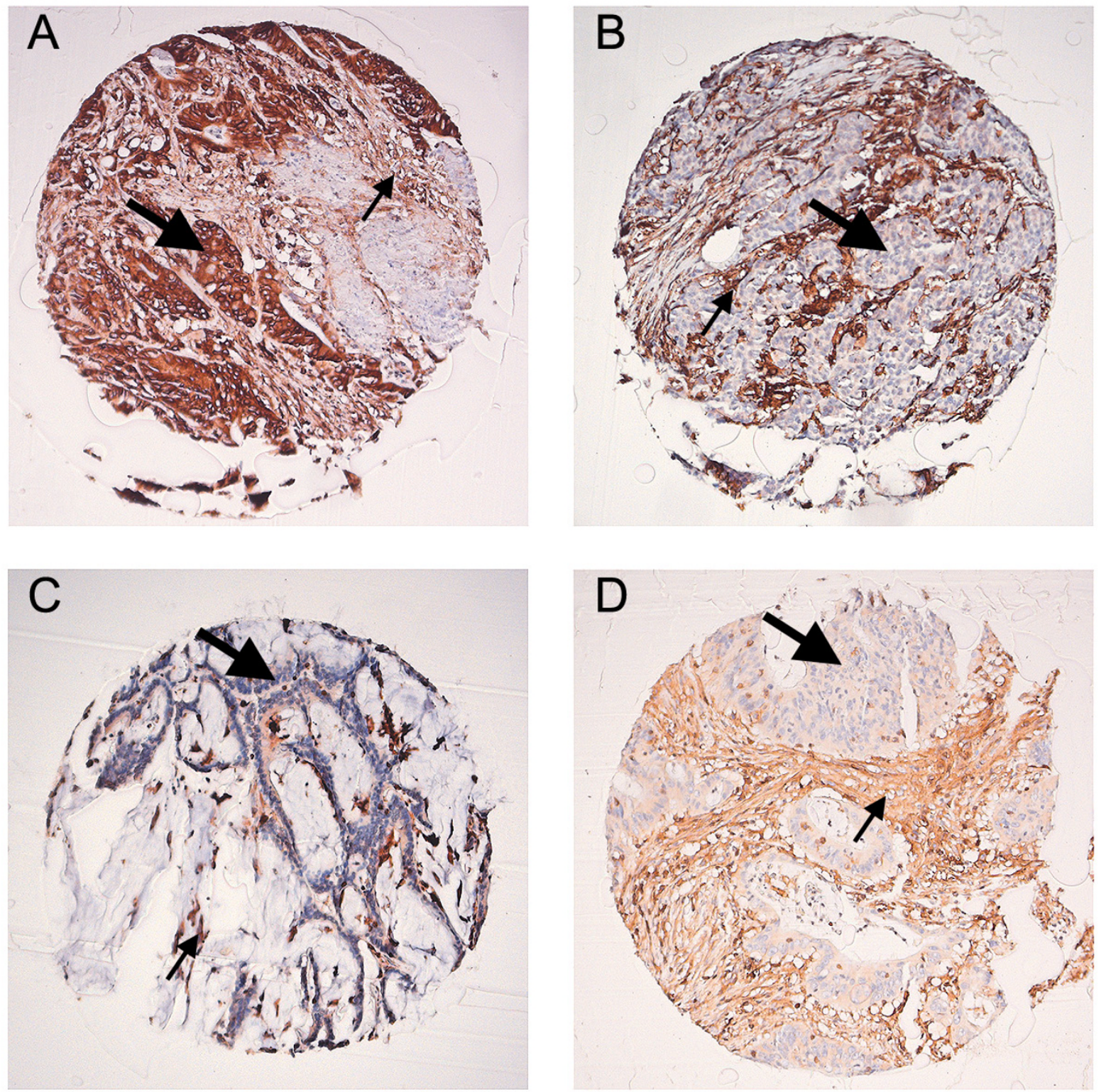

Figure I

Example of immunohistochemical analysis performed on the RST and HNPCC tumors (Amplification I0x). A, Positive expression of HLA class I antigens detected with the HCA2 antibody. The epithelial (large arrow) membranous expression of HLA class I antigens is identical to the lymphocytic infiltrate (small arrow). B, Loss of expression of HLA class I identified with the HCA 2 antibody. The lymphocytic infiltrate (small arrow) was used as a positive control to determine the loss of expression on the epithelial cells. C, Loss of expression of $\beta 2 \mathrm{~m}$ in a HNPCC case. D, Loss of expression of one of the APM members (Tapa$\sin$ ) in a RST case.

LMP7 ( 2 cases), and Calnexin and ERp57 (1 case). Loss of the LPM10 protein was detected in neither sporadic RST nor HNPCC tumors. The HNPCC cases h38 and h49 lost the expression of TAP2 and LMP7 respectively.

\section{LOH and frameshift analysis}

Polymorphic markers around the classical HLA genes (A, $B$ and $C$ ), TAP 1 and TAP2 genes were used to study $\mathrm{LOH}$ and reveal possible chromosomal aberrations that could 
Table 2: HLA, APM and $\beta 2 \mathrm{~m}$ expression in RST and HNPCC colon cancer

\begin{tabular}{|c|c|c|c|c|c|}
\hline & & & ALA' & APM loss $\ddagger$ & $\beta 2 \mathrm{~m}$ loss $\ddagger$ \\
\hline \multirow{4}{*}{$\begin{array}{c}\text { RST } \\
N=8 I\end{array}$} & MSS & + & 40 & 0 & 0 \\
\hline & $\begin{array}{l}N=48 \\
(59,3 \%)\end{array}$ & - & $8(16,7 \%)$ & $3(37,5 \%)^{*}$ & 0 \\
\hline & MSI-H & + & 13 & 0 & 0 \\
\hline & $\begin{array}{l}N=33 \\
(41,7 \%)\end{array}$ & - & $20(60,6 \%)$ & $7(35,0 \%)^{*}$ & I (5,0\%)* \\
\hline \multirow{2}{*}{$\begin{array}{c}\text { HNPCC } \\
N=75\end{array}$} & MSI-H & + & 43 & 0 & 0 \\
\hline & & - & $32(42,7 \%)$ & $2(6,3 \%)^{*}$ & I 5 (46,9\%)* \\
\hline
\end{tabular}

* - The percentage of cases that lost APM or $32 \mathrm{~m}$ expression is relative to the number of HLA negative cases of each subset $\dagger-$ HLA expression differs significantly between sporadic MSI-H and MSS tumors $(p<0.000 \mathrm{I})$ and between HNPCC and sporadic MSS tumors ( $\mathrm{H}<$ $0.005)$

$\ddagger-$ The association of HLA class I loss with that of $\beta 2 \mathrm{~m}$ and of APM components differs significantly ( $p<0.000 \mathrm{I})$ between sporadic RST and HNPCC tumors.

relate to loss of HLA class I expression (Figure 5A). In HNPCC cases, LOH analysis was only performed around the HLA genes since loss of the TAP1 and TAP2 proteins was rarely associated with HLA class I loss. LOH was more frequent in the MSS tumors (50\%) than in the MSI-H sporadic $(20 \%)$ and HNPCC (6\%) tumors with loss of HLA class I expression $(\mathrm{P}<0.05)$ (Figure 3, 4). Furthermore, the patterns of LOH in the MSS cases might indicate loss

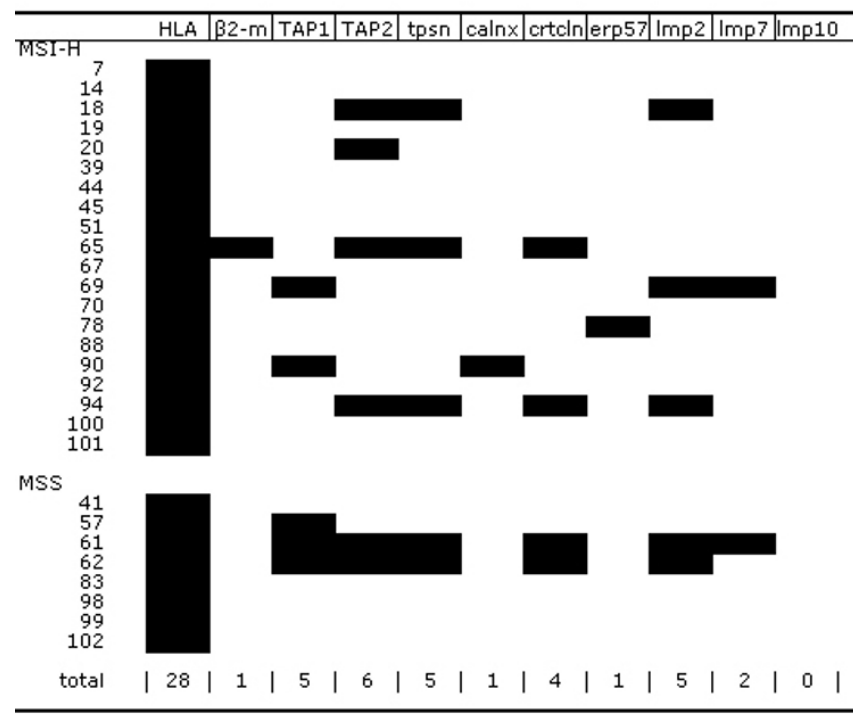

\section{Figure 2}

Loss of expression of $\beta 2 \mathrm{~m}$ and different APM members was detected by immunohistochemistry in the RST that presented with HLA loss. The shadowing (in black) is indicative for loss of expression of the respective molecules. (tpsn Tapasin, calnx - Calnexin, crtcln - Calreticulin) of the entire $6 \mathrm{p} 21.3$ region, in contrast to the MSI-H cases (hereditary and sporadic forms) where LOH seems to be limited.

Frameshift mutation screening of the microsatellite sequences present in the coding regions of the HLA class I, APM components and $\beta 2 \mathrm{~m}$ genes was performed on all cases with aberrant HLA class I expression (Figure 5B,C. However specific genes were only analyzed when lack of expression of the encoded proteins was detected by immunohistochemistry. Of the classical HLA class I genes only HLA-A and -B were analyzed since HLA-C does not carry any microsatellite repeat in its coding region. Ten RST cases and 20 HNPCC control cases with normal expression of $\beta 2 \mathrm{~m}$ and APM components were screened for frameshift mutations and none was detected.

Frameshift mutations were mainly found in the MSI-H cases (both sporadic and hereditary forms). At least one mutation in an APM component gene was found in 6 of 7 sporadic MSI-H tumors that lost expression of one or more APM components. The single sporadic MSI-H case that lost $\beta 2 \mathrm{~m}$ expression also presented with a single frameshift mutation in the $\beta 2 m$ gene. Of the 13 sporadic MSI-H cases in which loss of HLA class I expression was associated neither with APM component nor with $\beta 2 \mathrm{~m}$ loss as detected by immunohistochemical staining, one presented with a frameshift in an HLA gene (case 39, Figure 3, Table 3) while 3 other cases showed LOH of the markers adjacent the HLA genes (cases 7, 44 and 67). One frameshift mutation was found in the Tapasin gene in a MSS case (case 62). From 15 HNPCC tumors that lost $\beta 2 \mathrm{~m}$ expression at least one mutation was found in 8 cases (Figure 4). Three of the latter showed 2 mutations localized in different stretches. In the remaining 17 HNPCC 


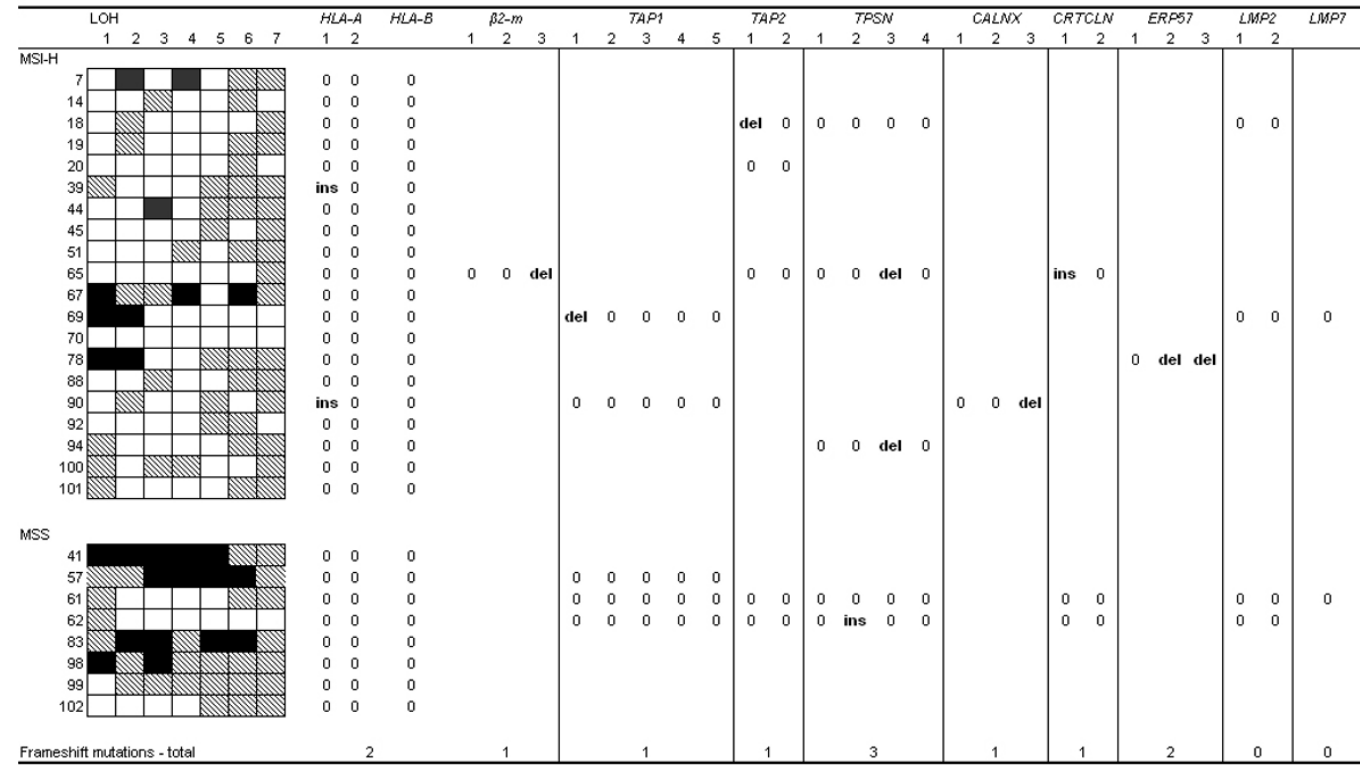

Figure 3

LOH and frameshift analysis was performed on sporadic RST that lost HLA class I expression. Only the tumors that presented with loss of one of the APM molecules or $\beta 2 \mathrm{~m}$ were subjected to fragment analysis in their respective genes. The following repeats were analyzed for frameshift mutations: HLA A: I - $4^{\text {th }}$ exon 7(C), 2 - $5^{\text {th }}$ exon $3($ GGA); HLA - B: 3(GA) \& 3(CA); $\beta 2 \mathrm{m:}$

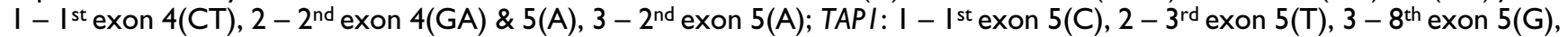
$4-1^{\text {th }}$ exon 5(G), 5 - I Ith exon 6(G) \& 5(A); TAP2: I - $2^{\text {nd }}$ exon 6(C), 2 - 9th exon 5(G); Tapasin: I $-2^{\text {nd }}$ exon 5(G), $2-3^{\text {rd }}$ exon 5(C), $3-4^{\text {th }}$ exon 6(C), $4-5^{\text {th }}$ exon 5(G); Calnexin: I $-7^{\text {th }}$ exon 5(A), $2-8^{\text {th }}$ exon 5(A), 3 - I th exon 8(T); Calreticulin: I $-3^{\text {rd }}$ exon 5(G), $6^{\text {th }}$ exon 5(C); ERp57: I - $5^{\text {th }}$ exon 6(T), $2-6^{\text {th }}$ exon 6(A), 3 - $13^{\text {th }}$ exon 6(C); LMP2: I - $2^{\text {td }}$ exon 5(G), $2-6^{\text {th }}$ exon 5(G); LMP7: Ist exon 6(C) (key: ins - insertion; del - deletion; 0 - no mutation). LOH analysis of the 6p chromosome was also performed with the following markers: I - MOGc, 2-D6S5I0, 3 - CI25, 4-CI4I, 5 - D6S2444, 6- TAPI, 7 - M2426 (Key: Black - Loss of heterozygosity; Striped - non informative marker; White - Retention of heterozygosity).

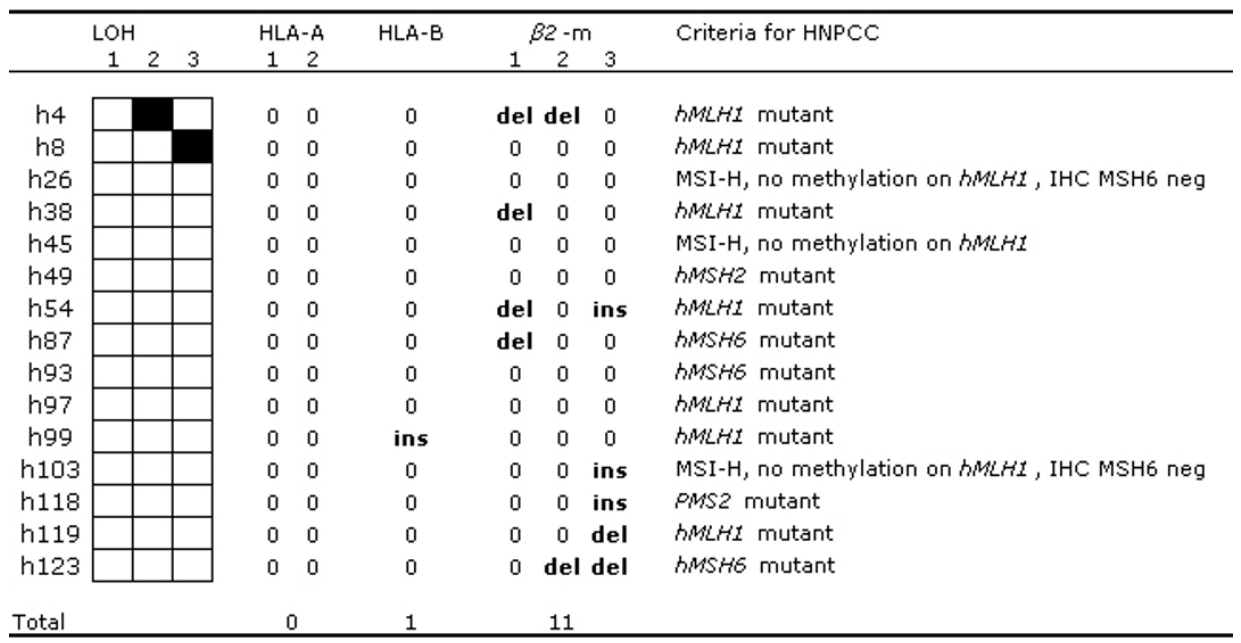

Figure 4

$\mathrm{LOH}$ and frameshift analysis was performed on HNPCC tumors that simultaneously lost HLA class I and $\beta 2 \mathrm{~m}$ expression. LOH markers: (see legend from Figure 3 for key). Frameshift markers:HLA A: I - $4^{\text {th }}$ exon 7(C) $2-5$ th exon 3 (GGA); HLA - B: 3(GA) \& 3(CA); $\beta 2 m$ : I - Ist exon 4(CT), 2 - 2nd exon 4(GA). \& 5(A), 3 - 2 ${ }^{\text {nd }}$ exon 5(A) (key: ins - insertion; del - deletion; 0 - no mutation; IHC -immunohistochemistry) 

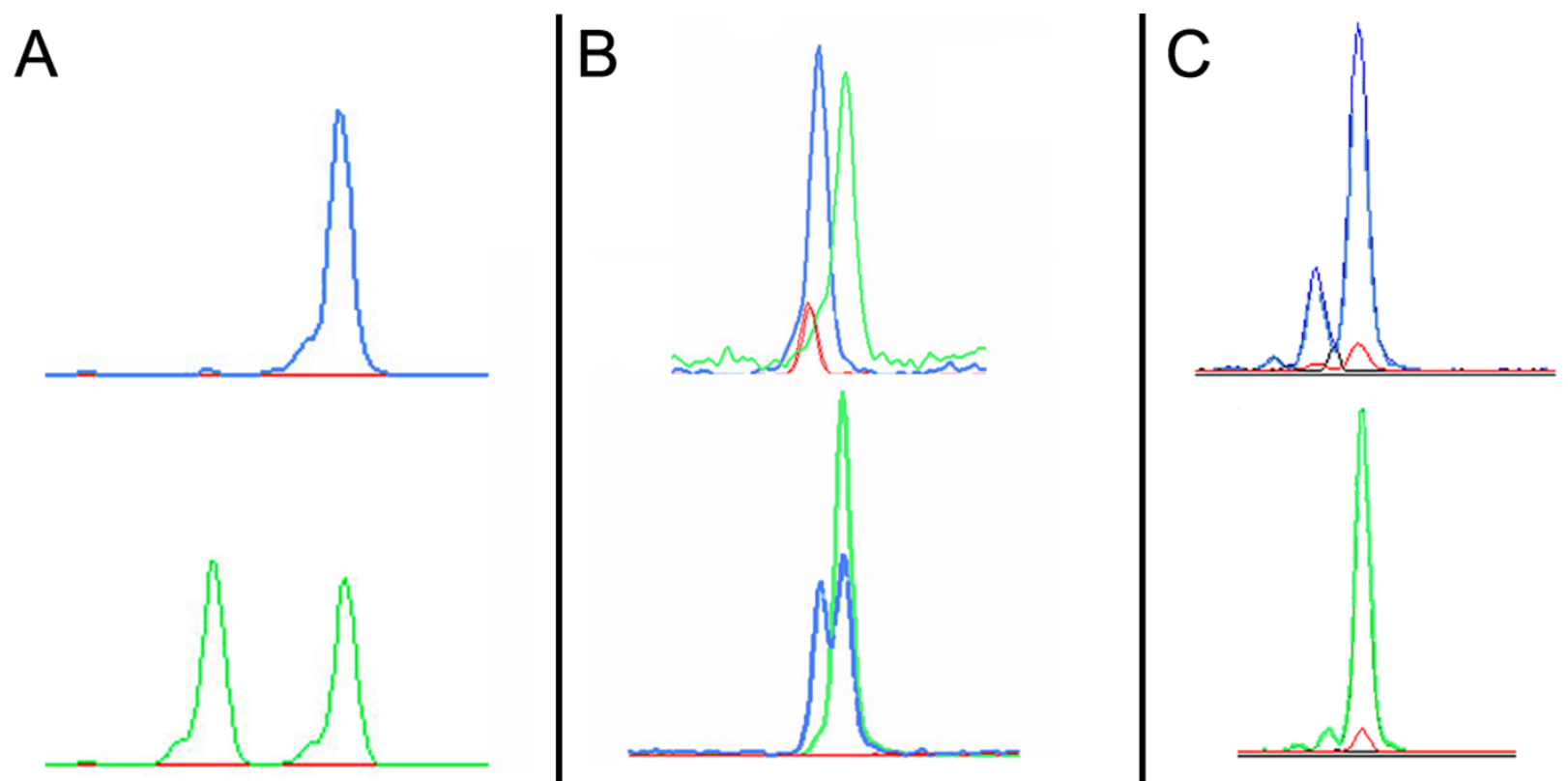

\section{Figure 5}

Genetic analysis performed on tumors that have lost HLA class I expression. The different peaks correspond to different sizes from the PCR-amplified products. Peaks corresponding to the normal samples are represented in green whereas tumor samples are represented in blue. A, LOH analysis performed on the RST 4I sample with the polymorphic marker CI4I. The total loss of a normal allele (on top) illustrates the technical advantage of using flow cytometric sorting to identify LOH events. B, Frameshift mutations identified in different members of the APM machinery. On top a homozygous deletion in the sample RST 65 on the $4^{\text {th }}$ exon of the Tapasin gene is shown. On the bottom, a heterozygous deletion in the sample RST I8 on the second exon of the TAP2 gene is shown. C, Frameshift mutation identified in one HNPCC case (h4) in the $2^{\text {nd }}$ exon of the $\beta 2 \mathrm{~m}$ gene. Because flow sorting was not performed in the HNPCC cases, we cannot determine whether the frameshifts are homo- or heterozygous due to contamination with normal DNA.

cases that solely lost HLA class I expression, only 4 showed genetic abnormalities. $\mathrm{LOH}$ was found in the HLA region in cases h16, h56 and h120 (data not shown). A frameshift mutation in one of the HLA genes (HLA B) was found in one case (h99, Figure 4). In neither of the 2 HNPCC cases that immunohistochemically lost the expression of one of the APM components an APM frameshift mutation was found.

\section{Discussion}

Abnormalities in HLA class I cell surface expression are commonly observed in tumors and are interpreted as a mechanism by which tumor cells evade the host immune system [1]. In colorectal cancer, especially in MSI-H tumors, the high degree of lymphocytic infiltrate in some cases may suggest an active immune response during tumor development $[41,42]$. Moreover, MSI-H tumors

Table 3: Frameshift mutations description in RST

\begin{tabular}{|c|c|}
\hline RST & Mutation description \\
\hline 18 & TAP2 (34I-346)dell - het \\
\hline 39 & HLA-A (62I-627)insI - het \\
\hline 65 & $\begin{array}{l}\beta 2 m(34 I-345) \text { dell - hom; Tapasin (I2I7-1222)del I - hom; Calreticulin } \\
(4 \mid 8-422) \text { ins I - hom }\end{array}$ \\
\hline 69 & TAPI (362-366)dell - hom \\
\hline 78 & ERp57 (675-680)del2 - hom; ERp57 (1459-1464)dell - hom \\
\hline 90 & HLA-A (62 I-627)ins I - het; Calnexin (1476-1483)delI - het \\
\hline 94 & Tapasin $(1217-1222)$ dell - het \\
\hline
\end{tabular}

ins - insertion; del - deletion; hom - homozygous; het - heterozygous; the numbers before and after del/ins indicate the location of the microsatellite repeat containing the frameshift mutation and the number of affected nucleotides respectively. 
might cause increased immune reactivity as a consequence of the high amounts of aberrant frameshift peptides they generate $[8,18]$. A selective pressure by CTLs upon these tumors would favor the outgrowth of tumor cells that lost HLA class I expression at the cell surface allowing them to surpass the action of the immune system.

Applying immunohistochemistry on tissue arrays, we compared HLA class I expression in both sporadic RST (MSI-H and MSS sub-groups) and HNPCC tumors. RST were chosen because of the high percentage of MSI-H cases in this specific tumor type [43]. Indeed, immunohistochemical staining with mAb showed that HLA class I loss was frequent in the MSI-H cases analyzed when compared to their MSS counterpart. This finding supports the hypothesis that MSI-H tumors face greater selective pressure to lose HLA class I expression, as described by Kloor et al[8]. However, we have shown for the first time that distinct molecular mechanisms underlie HLA class I loss in sporadic MSI-H and HNPCC colon cancers. In the latter, HLA class I loss was preferentially associated with that of $\beta 2 \mathrm{~m}$, while in the former HLA class I loss was associated with that of one or more APM components ( $\mathrm{p}<$ 0.0001).

We investigated the genetic abnormalities underlying the HLA class I loss of expression. They included LOH on chromosome region 6p21.3 (encompassing HLA class I and TAP genes), mutations in APM components and mutations in $\beta 2 \mathrm{~m}$.

Loss of heterozygosity at $6 \mathrm{p} 21.3$ was most prevalent in MSS tumors. This is consistent with the observation that these tumors frequently possess gross chromosomal aberrations and are often aneuploid [13]. Moreover, since LOH events in MSS tumors normally comprise large areas of a chromosome, $\mathrm{LOH}$ on 6p21 might not be a direct consequence of selective pressure directed to the loss of HLA expression but instead to other genes within the same chromosomal region. The general absence of $\mathrm{LOH}$ in MSI-H tumors suggests that this is not the major mechanism by which the cells abrogate HLA class I expression.

The genome's coding regions contain multiple microsatellite repeats, which are considered hotspots for mutations in mismatch repair-deficient tumors [43]. Such repeats are also present within the exons of the APM components, $\beta 2 m, H L A-A$ and HLA-B genes. In about half of the MSI-H cases, loss of expression of HLA class I was concordant with the detection of one or more mutations in these genes. We have discovered novel mutations in the antigen presenting machinery genes; Tapasin, Erp57, Calreticulin and Calnexin in colorectal cancer. Previous reports associated the loss of HLA class I expression in MSI-H tumors with defects on $\beta 2 \mathrm{~m}$ molecule [7,9]. However, the authors did not distinguish the sporadic/hereditary nature of the tumors that were studied. We cannot exclude that the MSI-H cases included in these studies were mainly HNPCC tumors.

The reason sporadic MSI-H tumors would target APM members for inactivation and HNPCC would target the $\beta 2 \mathrm{~m}$ chaperon is unclear. One possibility worth further exploration is that the various mutations suggest different immune-escape mechanisms for thwarting distinct antitumor responses. HNPCC tumors can have an age of onset before the $5^{\text {th }}$ decade of life while sporadic MSI-H tumors appear generally around the $7^{\text {th }}$ decade of life [43]; one would therefore predict that the alertness and robustness of the immune system would be higher in HNPCC patients leading to a stronger, or at least different selective pressure on the latter. Furthermore it has been recently suggested that the JC polyoma virus plays a role in the oncogenicity of colon tumors with an identical phenotype to sporadic MSI-H tumors [44]. Although speculative, the presence of the JC virus might be implicated in a different immune response between sporadic MSI-H and HNPCC tumors.

The advantages of different escape mechanisms (loss of APM members vs. abrogation of $\beta 2 \mathrm{~m}$ ) are not understood. The only known function of APM members is facilitating the expression of HLA classical molecules in complex with endogenous peptides. Thus, one would expect that only these HLA molecules would be affected by failure of the antigen processing machinery. On the other hand, it is accepted that cell surface expression of non-classical HLA molecules (e.g. HLA -G, -E) also depends on $\beta 2 \mathrm{~m}$, so the function of these highly specialized molecules would be compromised if $\beta 2 \mathrm{~m}$ were mutated or lost. These molecules might play an important role in regulation of immune cell activity by inhibiting or activating its function. Therefore, MSI-H sporadic tumors that have lost expression of both HLA and an APM component and HNPCC tumors with lost $\beta 2 \mathrm{~m}$ expression might behave differently or present a different kind of interaction with cells from the immune system. For instance, Yamamoto et al. have described a correlation between $\beta 2 \mathrm{~m}$ mutations and unfavorable prognosis in colorectal cancer

We separately analyzed the presence of the characteristic BRAF V600E somatic mutations in the RST cohort (data not shown). Forty-percent of MSI-H sporadic tumors presented with this mutation which was absent in the MSS tumors. It was previously described that this mutation is also absent in HNPCC tumors [46]. V600E was distributed equally between tumors that lost vs. retained expression of HLA class I in the sporadic MSI-H cases. 


\section{Conclusion}

HLA class I aberrations are found at varying frequencies in different colorectal tumor types and are caused by distinct genetic mechanisms. Chiefly, sporadic and hereditary MSI-H tumors follow different routes toward HLA class I loss of expression supporting the idea that these tumors follow different evolutionary pathways in tumorigenesis. The resulting variation in immune escape mechanisms may have repercussions in tumor progression and behavior.

\section{Competing interests}

The author(s) declare that they have no competing interests.

\section{Authors' contributions}

JWD - Contributed to the conception and design of the study, performed flow sorting procedure and was involved in the interpretation of data.

NM - Generated the RST array, performed the immunohistochemistry, flow sorting procedure, LOH and fragment analysis, was involved in the interpretation of data and drafting of the manuscript

SF - Contributed to the conception and design of the study, and critically reviewed the manuscript

MvP - Performed the MSI analysis on HNPCC cases and methylation-specific MLPA assay.

CC - Contributed to the conception and design of the study, and critically reviewed the manuscript

GJF - Contributed to the conception and design of the study, and to critical revision of the manuscript

TvW - Critically reviewed the manuscript.

HM - Contributed to the conception and design of the study, and is responsible for the study.

All authors read and approved the final manuscript.

\section{Acknowledgements}

This study was supported by the Dutch Cancer Society (grant number 2000/2 135). We thank Dr. Hans Vasen and Dr. Carli Tops for crucial information on the HNPCC cohort. We thank Dr. Jan Calame for providing us with RST tumors.

\section{References}

I. Melief CJM: Cancer immunology: Cat and mouse games. Nature 2005, 437:41-42.

2. Stevanovic S, Schild H: Quantitative aspects of T cell activation - peptide generation and editing by MHC class I molecule. Semin Immunol 1999, I I:375-384.

3. Algarra I, Garcia-Lora A, Cabrera T, Ruiz-Cabello F, Garrido F: The selection of tumor variants with altered expression of classi- cal and nonclassical MHC class I molecules: implications for tumor immune escape. Cancer Immunol Immunother 2004, 53:904-910.

4. Chang CC, Ferrone S: Immune selective pressure and HLA class I antigen defects in malignant lesions. Cancer Immunol Immunother 2006: I- I0.

5. Koopman LA, van der Slik AR, Giphart MJ, Fleuren GJ: Human leukocyte antigen class I gene mutations in cervical cancer. J Natl Cancer Inst 1999, 91: |669- I677.

6. Jordanova ES, Riemersma SA, Philippo K, Schuuring E, Kluin PM: beta(2)-microglobulin aberrations in diffuse large B-cell lymphoma of the testis and the central nervous system. Int / Cancer 2003, 103:393-398.

7. Bicknell DC, Kaklamanis L, Hampson R, Bodmer WF, Karran P: Selection for beta(2)-microglobulin mutation in mismatch repair-defective colorectal carcinomas. Curr Biol 1996, 6: $1695-1697$.

8. Kloor M, Becker C, Benner A, Woerner SM, Gebert J, Ferrone S, Knebel Doeberitz M: Immunoselective Pressure and Human Leukocyte Antigen Class I Antigen Machinery Defects in Microsatellite Unstable Colorectal Cancers. Cancer Res 2005, 65:6418-6424.

9. Cabrera CM, Jimenez P, Cabrera T, Esparza C, Ruiz-Cabello F, Garrido F: Total loss of MHC class I in colorectal tumors can be explained by two molecular pathways: beta(2)-microglobulin inactivation in MSI-positive tumors and LMP7/TAP2 downregulation in MSI-negative tumors. Tissue Antigens 2003, 61:211-219.

10. Ferris RL, Whiteside TL, Ferrone S: Immune Escape Associated with Functional Defects in Antigen-Processing Machinery in Head and Neck Cancer. Clin Cancer Res 2006, I 2:3890-3895.

II. Seliger B, Atkins D, Bock M, Ritz U, Ferrone S, Huber C, Storkel S: Characterization of human lymphocyte antigen class I antigen-processing machinery defects in renal cell carcinoma lesions with special emphasis on transporter-associated with antigen-processing down-regulation. Clin Cancer Res 2003, 9:1721-I727.

12. Klein J, Sato A: The HLA System- First of Two Parts. N Engl J Med 2000, 343:702-709.

13. Takayama T, Miyanishi K, Hayashi T, Sato Y, Nirrsu Y: Colorectal cancer: genetics of development and metastasis. J Gastroenterol 2006, 41: I85-192.

14. Gervaz P, Bucher P, Morel P: Two colons-two cancers: Paradigm shift and clinical implications. J Surg Oncol 2004, 88:26I-266.

15. Boland CR, Thibodeau SN, Hamilton SR, Sidransky D, Eshleman JR, Burt RW, Meltzer SJ, Rodriguez-Bigas MA, Fodde R, Ranzani GN, Srivastava S: A National Cancer Institute Workshop on Microsatellite Instability for cancer detection and familial predisposition: development of international criteria for the determination of microsatellite instability in colorectal cancer. Cancer Res 1998, 58:5248-5257.

16. Shin KH, Park YJ, Park JG: Mutational Analysis of the Transforming Growth Factor \{beta\} Receptor Type II Gene in Hereditary Nonpolyposis Colorectal Cancer and Early-onset Colorectal Cancer Patients. Clin Cancer Res 2000, 6:536-540.

17. Umar A, Risinger JI, Hawk ET, Barrett JC: Guidelines - Testing guidelines for hereditary non-polyposis colorectal cancer. Nat Rev Cancer 2004, 4: I53-I 58.

18. Linnebacher M, Gebert J, Rudy W, Woerner S, Yuan YP, Bork P, Doeberitz MV: Frameshift peptide-derived T-cell epitopes: a source of novel tumor-specific antigens. Int J Cancer 200I, 93:6-II.

19. Maleno I, Cabrera CM, Cabrera T, Paco L, Lopez-Nevot MA, Collado A, Ferr+'n A, Garrido F: Distribution of HLA class I altered phenotypes in colorectal carcinomas: high frequency of HLA haplotype loss associated with loss of heterozygosity in chromosome region 6p2 I. Immunogenetics 2004, 56:244-253.

20. Watson NFS, Ramage JM, Madjd Z, Spendlove I, Ellis IO, Scholefield $\mathrm{H}$, Durrant LG: Immunosurveillance is active in colorectal cancer as downregulation but not complete loss of MHC class I expression correlates with a poor prognosis. Int J Cancer 2006, I I 8:6-10.

21. Cabrera T, Collado A, Fernandez MA, Ferron A, Sancho J, RuizCabello F, Garrido F: High frequency of altered HLA class I phenotypes in invasive colorectal carcinomas. Tissue Antigens 1998 , 52: || $\mid 4-123$. 
22. Dierssen JW, de Miranda N, Mulder A, van Puijenbroek M, Verduyn W, Claas F, van de Velde C, Jan Fleuren G, Cornelisse C, Corver W, Morreau $\mathrm{H}$ : High-resolution analysis of HLA class I alterations in colorectal cancer. BMC Cancer 2006, 6:233.

23. Young J, Simms LA, Biden KG, Wynter C, Whitehall V, Karamatic R, George J, Goldblatt J, Walpole I, Robin SA, Borten MM, Stitz R, Searle J, McKeone D, Fraser L, Purdie DR, Podger K, Price R, Buttenshaw R, Walsh MD, Barker M, Leggett BA, Jass JR: Features of colorectal cancers with high-level microsatellite instability occurring in familial and sporadic settings - Parallel pathways of tumorigenesis. Am J Pathol 2001, I59:2107-2II6.

24. van Puijenbroek $M$, van Asperen $C$ J, van Mil $A$, Devilee $P$, van Wezel T, Morreau H: Homozygosity for a CHEK2* I I00delC mutation identified in familial colorectal cancer does not lead to a severe clinical phenotype. J Pathol 2005, 206: I 98-204.

25. Hendriks Y, Franken P, Dierssen JW, de Leeuw W, Wijnen J, Dreef E, Tops C, Breuning M, Brocker-Vriends A, Vasen H, Fodde R, Morreau $\mathrm{H}$ : Conventional and Tissue Microarray Immunohistochemical Expression Analysis of Mismatch Repair in Hereditary Colorectal Tumors. Am J Pathol 2003, I 62:469-477.

26. Nygren $\mathrm{AOH}$, Ameziane N, Duarte HMB, Vijzelaar RNCP, Waisfisz Q, Hess CJ, Schouten JP, Errami A: Methylation-specific MLPA (MS-MLPA): simultaneous detection of CpG methylation and copy number changes of up to $\mathbf{4 0}$ sequences. Nucleic Acids Res 2005, 33:

27. Code Proper Secondary Use of Human Tissue [http:// www.federa.org/?s $=1 \& m=78 \& p=\& v=4]$

28. Stam NJ, Spits H, Ploegh HL: Monoclonal antibodies raised against denatured HLA-B locus heavy chains permit biochemical characterization of certain HLA-C locus products. J Immunol 1986, I 37:2299-2306.

29. Sernee MF, Ploegh HL, Schust DJ: Why certain antibodies crossreact with HLA-A and HLA-G: Epitope mapping of two common MHC class I reagents. Mol Immunol I 998, 35: I77-I88.

30. Perosa F, Luccarelli G, Prete M, Favoino E, Ferrone S, Dammacco F: \{beta\}2-Microglobulin-Free HLA Class I Heavy Chain Epitope Mimicry by Monoclonal Antibody HC-I0-Specific Peptide. J Immunol 2003, I 71:1918-1926.

31. Ogino T, Wang $X$, Kato S, Miyokawa N, Harabuchi $Y$, Ferrone S Endoplasmic reticulum chaperone-specific monoclonal antibodies for flow cytometry and immunohistochemical staining. Tissue Antigens 2003, 62:385-393.

32. Bandoh N, Ogino T, Cho HS, Hur SY, Shen J, Wang X, Kato S, Miyokawa N, Harabuchi Y, Ferrone S: Development and characterization of human constitutive proteasome and immunoproteasome subunit-specific monoclonal antibodies. Tissue Antigens 2005, 66:185-194.

33. Wang X, Campoli M, Cho HS, Ogino T, Bandoh N, Shen J, Hur SY, Kageshita T, Ferrone S: A method to generate antigen-specific mAb capable of staining formalin-fixed, paraffin-embedded tissue sections. J Immunol Methods 2005, 299:|39-|5I.

34. Corver WE, ter Haar NT, Dreef EJ, Miranda NFCC, Prins FA, Jordanova ES, Comelisse C], Fleuren G]: High-resolution multiparameter DNA flow cytometry enables detection of tumour and stromal cell subpopulations in paraffin-embedded tissues. J Pathol 2005, 206:233-24I.

35. Vanmuijen GNP, Ruiter DJ, Warnaar SO: Coexpression of Intermediate Filament Polypeptides in Human-Fetal and Adult Tissues. Lab Invest 1987, 57:359-369.

36. Jordanova ES, Corver WE, Vonk MJ, Leers MPG, Riemersma SA, Schuuring E, Kluin PM: Flow cytometric sorting of paraffin-embedded tumor tissues considerably improves molecular genetic analysis. Am J Clin Pathol 2003, I 20:327-334.

37. de Jong $A E$, van Puijenbroek $M$, Hendriks $Y$, Tops $C$, Wijnen J, Ausems MGEM, Meijers-Heijboer $H$, Wagner $A$, van Os TAM, Brocker-Vriends AHJT, Vasen HFA, Morreau H: Microsatellite Instability, Immunohistochemistry, and Additional PMS2 Staining in Suspected Hereditary Nonpolyposis Colorectal Cancer. Clin Cancer Res 2004, 10:972-980.

38. dbMHC [http://www.ncbi.nlm.nih.gov/mhc/]

39. de Leeuw WJF, van Puijenbroek M, Merx R, Wijnen JT, BrockerVriends AHIT, Tops C, Vasen $\mathrm{H}$, Cornelisse $\mathrm{C}$, Morreau $\mathrm{H}$ : Bias in detection of instability of the (C) 8 mononucleotide repeat of MSH6 in tumours from HNPCC patients. Oncogene 200I, 20:624I-6244.
40. Devilee P, Cleton-Jansen AM, Cornelisse Cl: Ever since Knudson. Trends Genet 2001, I 7:569-573.

41. Phillips AB: Tumour-infiltrating lymphocytes in colorectal cancer with microsatellite instability are activated and cytotoxic. BrJ Surg 2004, 9 I:469-475.

42. Dolcetti R, Viel A, Doglioni C, Russo A, Guidoboni M, Capozzi E, Vecchiato N, Macri E, Fornasarig M, Boiocchi M: High prevalence of activated intraepithelial cytotoxic $T$ lymphocytes and increased neoplastic cell apoptosis in colorectal carcinomas with microsatellite instability. Am J Pathol I999, I 54:|805-I8I3.

43. Ward R, Meagher A, Tomlinson I, O'Connor T, Norrie M, Wu R, Hawkins N: Microsatellite instability and the clinicopathological features of sporadic colorectal cancer. Gut 200I, 48:821-829.

44. Goel M, Li MS, Nagasaka T, Shin SK, Fuerst F, Ricciardiello L, Wasserman L, Boland CR: Association of JC virus T-antigen expression with the methylator phenotype in sporadic colorectal cancers. Gastroenterology 2006, I30:1950-1961.

45. Yamamoto H, Yamashita K, Perucho M: Somatic mutation of the beta(2)-microglobulin gene associates with unfavorable prognosis in gastrointestinal cancer of the microsatellite mutator phenotype. Gastroenterology 200I, I 20: I565-I567.

46. Domingo $E$, Laiho $P$, Ollikainen $M$, Pinto $M$, Wang $L$, French $A$, Westra J, Frebourg T, Espin E, Armengol M, Hamelin R, Yamamoto $H$, Hofstra RMW, Seruca R, Lindblom A, Peltomaki P, Thibodeau SN, Aaltonen LA, Schwartz S: BRAF screening as a low-cost effective strategy for simplifying HNPCC genetic testing. J Med Genet 2004, 41 :664-668.

\section{Pre-publication history}

The pre-publication history for this paper can be accessed here:

http://www.biomedcentral.com/1471-2407/7/33/prepub
Publish with Biomed Central and every scientist can read your work free of charge

"BioMed Central will be the most significant development for disseminating the results of biomedical research in our lifetime. "

Sir Paul Nurse, Cancer Research UK

Your research papers will be:

- available free of charge to the entire biomedical community

- peer reviewed and published immediately upon acceptance

- cited in PubMed and archived on PubMed Central

- yours - you keep the copyright
BioMedcentral 